\title{
Policy Framework and Management of Sustainable Macroeconomic Stability in Nigeria: Processes, Challenges and Prospects
}

\author{
Modinat O. Olusoji (Corresponding author) \\ School of Postgraduate Studies \\ Centre for Management Development \\ P.M.B. 21578, Ikeja, Lagos - Nigeria \\ Tel: 234-805-607-0749Ｅ-mail: olusojincema@yahoo.com
}

Received: July 1, 2014 Accepted: August 5, 2014 Published: September 22, 2014

doi:10.5296/ijssr.v2i2.6340

URL: http://dx.doi.org/10.5296/ijssr.v2i2.6340

\begin{abstract}
This paper examined the policy framework for macroeconomic stability in Nigeria from 1979 to date, observing the coordination of monetary and fiscal policies in Nigeria by looking at the purpose of the broad macroeconomic objectives as well as the key tools of economic management. The paper discusses, among others, the review of major policy framework in Nigeria; issues and performance of the monetary and fiscal policies framework; and the challenges of the monetary and fiscal policies management in Nigeria. The paper concludes that due process and discipline should be honestly restored in governance to avoid unnecessary policy failure while the fight against corruption should be intensified through speedy prosecution of cases in courts to assist in sending the right signals to corrupt government officials.
\end{abstract}

Keywords: Nigeria; policy framework; macroeconomic stability; management; monetary policy; fiscal policy

\section{Introduction}

Macroeconomic stability deals with the process of attaining the four major objectives of economic policy. These objectives are price stability, full employment, balance of payment equilibrium and sustainable economic growth (Ojo, 2000). The purpose of price stability objective is to restrict increase in domestic prices periodically to a moderate level so that inflation rate can be restricted to a single digit. Full employment deals with keeping the economy at the natural rate of unemployment. Balance of payment has to do with the record of 
a country's transactions with the rest of the world and a country has to watch the movement in these transactions so as to take care of disequilibrium on a regular basis while sustainable economic growth is the change in the gross domestic product that is sustained over a long period of time. Failure to achieve these objectives will amount to instability in any economy.

The main objectives of Government's economic policy are the achievement of sustainable economic growth together with a high level of employment that will lead to improvements in the standard of living of the populace.

Policy frameworks are guidelines that are taken into consideration when making rules to guiding overall direction to planning and development of an organization.

Monetary policy and exchange rate are key tools in economic management and in macroeconomic stabilization and adjustment process in Nigeria, where non-inflationary growth and international competitiveness have become major policy targets (Busari et al., 2010). According to Oluba (2008), monetary policy is a way of managing money in an economy and it involves the modification of the quantity of money by the central bank for the purpose of achieving macroeconomic targets in the four major objectives of the economic policy. To this end, the goal is stable and low inflation among others. Generally, the combination of fiscal and monetary policies is to bring about achievement of macroeconomic stability. However, the superiority of each of them on the achievement of macroeconomic stability had been subject of debates over the years. The Keynesians were of the opinion that fiscal policy is more potent than monetary policy while the monetarists led by Milton believed the other way round (Folawewo \& Oshinubi, 2006).

The objective of monetary policy is the achievement of domestic and external price stability. Exchange rate is used as policy tool in ensuring external stability by impacting on the outcome of stabilization measures and debt management strategies (Caballero \& Corbo, 1989; Busari \& Olayiwola, 1999).

Over the years, macroeconomic dynamics in Nigeria has been dominated by fiscal instability resulting from strong deficit and debt due to government revenue volatility. To this end, monetary authority had to implement neutralizing monetary policies leading to macroeconomic instability (Obinyeluaku, 2006). A stable macroeconomic environment is capable of reducing management problems and improving the prospects of planning effectively for sustainable growth and development. However, Fiscal recklessness in governance can cause inflation that contradicts the monetary policy objective of price stability. This has the potentials of destabilizing the macroeconomic environment thereby retarding economic productivity and development (Ezeoha \& Uche, 2006).

The purpose of this paper is to highlight the policy framework for macroeconomic stability in Nigeria from 1979 to date and discuss the challenges and way forward. Following the introduction is the review of major policy framework in Nigeria. Section 3 highlights the issues and performance of the monetary and fiscal policies framework while section 4 discusses the challenges of the monetary and fiscal policies management in Nigeria. Section 5 contains the way forward. 


\section{Review of Major Macroeconomic Policy Frameworks}

\subsection{Monetary Policy Framework}

Monetary policy process as discussed by Uchendu (2009), is fairly complex and involves monetary policy committee (MPC): setting objectives, meeting regularly to assess the economic condition and outlook, making decision to lower, maintain or raise policy rate, press release, using open market operation for liquidity management in conformity with the policy rate, reporting and feedback, evaluation of outcomes and policy review.

The Central Bank of Nigeria has implemented monetary policy using various combinations of direct controls and indirect controls (market-based controls) since its inception in 1959 (Chuku, 2009). Chuku argued that the era of direct controls was a remarkable period in monetary policy management in Nigeria. This was because there were a lot of structural changes such as shift in the economic base from agriculture to petroleum, the execution of the civil war of 1967 to 1970 , the oil boom of the 1970s and the glut of early 1980s as well as the introduction of the Structural Adjustment Programme (SAP). Moreover, the CBN's monetary policies focused on fixing and controlling interest rates and exchange rates, selective sectoral credit allocation, manipulation of the discount rate and moral suasion.

The framework for CBN monetary policy prior to SAP was not effective because of lack of autonomy as well as the political influence of the ministry of finance. This made the bank to rely largely on the instrument of sectoral credit allocation; credit ceilings and cash reserve requirements; administrative fixing of interest and exchange rates; including imposition of special deposits. To this end, monetary targets were hardly realized during this period and to the extent there were a lot of distortions and bottlenecks in resource allocation, bringing about inefficiencies in resource allocation and utilization (Nnanna, 2001). With the implementation of SAP in 1986, however, the bank changed from the direct monetary control to an indirect approach and made use of market instruments for monetary policy. The CBN then commenced market friendly technique of monetary policy implementation, which was later reinforced by the CBN's amendment Act that granted it full autonomy to take full charge of monetary policy in Nigeria.

The SAP period (1986 to 2001) witnessed short-term monetary policy framework under which Open market operation (OMO) was conducted with the use of Nigerian Treasury Bills (NTBs) which was complemented by cash reserves requirement (CRR) and the liquidity ratio (LR) as the instruments of monetary policy among others. Moreover, there was interest rate deregulation policy through the proactive adjustment of minimum rediscount rate (MRR) to signal policy direction consistent with liquidity conditions.

On the external front, there was a unification of official and inter-bank exchange rates in 1999. Year 2002 witnessed commencement of a two-year medium-term monetary policy framework by the CBN with the purpose of freeing monetary policy from the problem of time inconsistency and minimizing over-reaction due to temporary shocks. The major objectives of monetary policy since that time were to ensure a single-digit inflation rate and maintain a stable exchange rate of the naira. In addition, there had been a focus on the need to have a more 
competitive financial sector that will bring about improvement in the payments system (CBN, 2010).

In 2004, the CBN introduced the recapitalization of banking sector for the purpose of minimizing macroeconomic instability arising from banking systemic distress; motivating intermediation through the deepening of the capital market; financing productive sector growth in the private sector, particularly non-oil growth; minimizing the counterfactual shocks of creating distortions in the money markets and the financial system; and encouraging investment inflows through effective participation of the industry in the global financial system.

The post banking consolidation exercise brought about monetary policy strategy that was geared towards removal or cancellation of ways and means advances, cutting down TB's holding by $\mathrm{CBN}$, liquidity mop-up operations through frequent $\mathrm{OMO}$ sales, unremunerated reserve requirements, improved coordination between the monetary and the fiscal authorities, restructuring of debt instruments, increased deregulation of foreign exchange market, and occasional foreign exchange swap (CBN, 2010)

\subsection{Fiscal Policy Framework in Nigeria}

The fiscal policy is an attempt by the government to control revenue and expenditure for the purpose of achieving macro- economic growth. It is the combination of measures in government revenue and expenditure to achieve overall economic objectives of a nation. The fiscal policy used includes taxation, public expenditure, relief, concessions and fiscal incentive policies among others. Nigeria had experienced a long history of macroeconomic instability and fiscal imbalances which was influenced by large fiscal deficits-GDP ratio for several years. This is because, its fiscal policy has been heavily influenced by oil driven volatility by impacting on revenue and expenditure.

During the periods of high oil prices, revenue and expenditure increased sharply and reduces at the period of dwindled oil prices. For example, 1979 to 1982, 1991 to 1992 and 2000 to 2002 witnessed increased revenue and expenditures while the period of fall in oil prices witnessed reduction in revenue and expenditure. This is because Nigeria is a monoculture economy, depending on above $70 \%$ of revenue from oil and gas. The implication of such fiscal policies is the transmission of the oil volatility to the rest of the economy with negative implication for growth and development (Baunsgaard, 2003), and as such there was weakness in the public expenditure management system across the nation. This weakness was characterized by uncontrolled spending with huge government deficits, financed mostly by monetary growth, large recurrent spending and debt service costs, low implementation of the capital budget, poor accountability and transparency, weak monitoring, auditing and reporting. Despite the huge oil resources that have been utilized over the years, there is little to show for it in terms of economic development, which represents a challenge to fiscal management resulting from inefficient use of public resources. This calls for appropriate fiscal policy formulation by providing a framework for a more suitable and predictable budget. Prior to 1999, the country was under military rule during which the budget process was thrown into total disarray. The major defects in the fiscal policy process include poorly conceived projects and programmes; 
poor linkage between spending and development priorities; poor accountability and transparency; low level of implementation of the capital budget; weak monitoring, auditing and reporting; reliance on largely manual and dated procedures among others. Invariably, it has not been possible for the budget to perform its role effectively in terms of resource allocation and contribution to economic growth and development. With the advent of NEEDS in 2003 however, there was a relative prudence in the macroeconomic management through the introduction of medium-term fiscal-expenditure framework (MTEF) through a focus on macroeconomic strategy and prioritization of expenditure.

In addition, several reforms were embarked on to address the issue of corruption, transparency and accountability among others. The main objective of the macroeconomic reform was to stabilize the Nigerian economy through improving budgetary planning and execution, and providing a platform for sustained economic diversification and non-oil growth. There was adoption of an oil price-based fiscal rule in which government expenditure was based on a prudent oil price benchmark. To this end, revenue above reference prices were kept in excess crude account to delink government expenditures from oil revenue earnings and ensure that the external shocks are not transmitted into the economy (Okonjo Iweala \& Osafo- Kwaako, 2007).

\section{Issues and Performance under Fiscal and Monetary Policy Frameworks}

\subsection{Performance of Fiscal Policy}

The past two decades have witnessed a considerable increase in government indebtedness in Nigeria. Beyond the issue of poor quality of public expenditure, the ability to save windfalls from excess crude oil proceeds by the government remains critical in ensuring that government expenditure is maintained at a sustainable level and consistent with the absorptive capacity of the economy. There has been volatility in the movement in oil prices since 1981 when the share of oil in government revenue had been fluctuating. It fluctuated from 64 percent in 1981 to 83 percent in 2008 and fell to 73.9 percent in 2010. This created instability in revenue and expenditures thereby affecting spending on health and educational services. The situation is made worse by the kind of intergovernmental finance in place in the country where the state and local government have to look up to the federal government for their allocation. The windfall from oil revenue between 1990 and 1992 culminated into rapid increase in government spending, which averaged about 21 percent of GDP during that period. However, with the crisis in the oil market in the subsequent years, oil receipts were inadequate to meet increasing levels of spending being reinforced by political pressures. To this end government resorted to ways and means advances from the central bank to finance the huge deficits. Despite the fact that the democratically elected government in 1999 adopted policies to restore fiscal discipline, the rapid monetization of foreign exchange earnings between 2000 and 2004, culminated into another period of oil windfall that resulted in increases in government spending. Government spending increased from 14 percent in 2002 to 19 percent of GDP in 2005 as a result of extra budgetary expenditure which were not directed towards capital and socio- economic sectors. 
To this end, there was adoption of an oil price-based fiscal rule in which government expenditure was based on a prudent oil price benchmark. To this end, revenue above reference prices were kept in excess crude account to ensure that government expenditures are not linked to oil revenue earnings and thereby ensure that the external shocks are not transmitted into the economy. This adoption resulted in significant public savings for the government. Gross excess crude savings was about $\$ 6.35$ billion and $\$ 17.68$ billion in 2004 and 2005 respectively. The period of 2003 to 2006 witnessed increases in foreign reserves from $\$ 7.5$ billion at the end of 2003 to about $\$ 38$ billion in July 2006 .

MTEF was introduced in 2005 to place emphasis on multi-year (three years) budgeting. The three-year budgeting approach aimed at linking policy development with resources over time, creating predictable medium-term planning environment, providing framework for assessing priorities, and fostering the credibility of the fiscal strategy by making explicit the assumptions on which projections and prioritization are based. However, MTEF requires an appropriate policy and institutional framework which addresses the long-term goals of the nation.

The improvement in the implementation of fiscal policy has provided a stable macroeconomic environment that is crowding in private sector participation in the domestic economy. For example, credit to the private sector grew by 30.8 percent in 2005 , exceeding the target growth rate of 22 percent (Table 1). Moreover, net credit to the federal government declined by 37 percent compared with the target decline of 10.9 percent (Table 1). This fall was attributed to a decline in the central bank's holding of treasury securities. However, there was a reverse trend in 2009 and 2011 when the actual exceeded the targets. In spite of the advantages of the medium-term expenditure framework, its adoption should not be regarded as the panacea for fiscal weaknesses and mismanagement in an economy. Olomola (2009) argued that MTEF requires persistent political commitment which in turn requires purposeful leadership to succeed. Moreover, the political leadership should have a good grasp of the direction to which the economy should be propelled to satisfying the yearnings of the people.

\subsection{Monetary Policy in Nigeria}

Table 1 below presents the gap between the Central Bank's monetary targets and the outcomes. The fact revealed in the table questions the role and effectiveness of monetary policy in the context of Nigeria's peculiar fiscal structure.

The review period was characterised by a significant level of monetary instability caused by excessive expansion of domestic liquidity through the increase in credit to the government by ways and means advances. Between 1988 and 1991, narrow money supply (M1) was used by the $\mathrm{CBN}$ as the intermediate monetary target. During those four years, M1 was programmed to grow at an average of 14.3 percent annually. However, the actual increase in M1 was 36.7 percent per annum. The largest deviations of outcomes from targets occurred respectively in 1988 and 1990 with 26.9 and 31.9 percentage points. The broad money supply (M2) became the intermediate monetary target from 1991. Meanwhile, the actual increase of M2 has been consistently higher than the targets in each of the last several years. In fact, 1999 and 2000 witnessed a triple fold growth rate compared with the target. In 2001, monetary base growth 
was more than 2 times the target while that of 2003 was 24 percent compared with a target of 15 percent.

The incidence of excessive expansion were very large during the review period particularly between 1992 and 1994, with the exception of the period of 1996 to 1998 when the actual increases in M2 exceeded the targets by an annual average of only 1.6 percentage points. Price stability is one of the most fundamental contributions of monetary policy to macroeconomic stability. The high rate of money growth has fuelled inflation, which averaged almost 26 percent a year between 1980 and 2001. Incidentally, the periods where the quantitative targets were not specifically set witnessed spiral inflation rates. During the period of 1986 to 1990, and 1994, the policy statement on inflation rate was specified as "significantly reduce/moderate the rate of inflation". From 2002 to 2005, the inflation rate remained at 2 digits, but only on few occasions were the targets met. In fact, Nigeria is yet to meet one of the West African Monetary Zone convergence criteria which is inflation rate that is less than 10 percent since 2008.

Bank credit to the domestic economy was the major source of the rapid monetary expansion except in 1990 when the source shifted to the foreign assets (net) of the banking system. During the period of review, actual increases in domestic credit were excessive particularly in 1992 to 1994, 1998, 2001, 2007 and 2008, except for the period 1995 to 1997, in which the actuals were below 20 percent. Increases in credit to the private sector were quite moderate during the period and were indeed below the targets stipulated for 1993, 1996, 1997 to 1998, 2002, 2003, 2009, 2010 and 2012. To this end, the main source of the rapid credit expansion to the economy was expansion of credit to the government. The implication if this is that the government crowded out the private sector, thereby discouraging investment. Apart from 1986, 1989 and 1995 to 1997 when actual levels of credit to the government declined as against the target, there was excessive credit to the government. It is necessary to note those years that the target of 0 or less percent growth rate was stipulated in credit to the government. Those years were 1991, 1994, 1999, and 2003, 2005, and 2007 to 2003. While credit to the government declined in 1995 to 1997 , it rose by $31.9,209.4,74.0,129.9103 .2,55.6,201.9,95.2$, and 6,320.6 percent in 1988, 1990, 1991, 1992, 1993, 1994, 1998, 2001 and 2002 respectively. The high rates of liquidity expansion as reported were associated with poor macroeconomic performance. The heavy borrowing by the government from the banking system was reflected in rising fiscal deficit to GDP ratio (Ojo, 2000). The persistence of disparity between the targets and outcomes is as a result of budget deficit financing and the inability of the Central Bank to sterilize the liquidity impact of government spending. However, a slight improvement in the macroeconomic performance is as a result of the adoption of an oil-price based fiscal rule, which led to creation of "the excess crude oil account" that have been used to regulate expenditure; the introduction of a MTEF; the adoption of MTSS to guide the budgetary process, the use of annual fiscal strategy paper, transparency and accountability issue that led to the publication of the share of revenue of the three tiers of government from the federation account on monthly basis, due process mechanism in public procurement, which eventually led to enactment of procurement act; and adoption of the Extractive Industries Transparency Initiative (Shamsuddeen, 2008). 
Table 1. Targets and Outcomes of Fiscal and Monetary Policies Indicators in Nigeria 1980 to 2012

\begin{tabular}{|c|c|c|c|c|c|c|c|c|c|c|c|c|}
\hline \multirow[t]{2}{*}{ Year } & \multicolumn{2}{|c|}{$\begin{array}{l}\text { Credit to Private } \\
\text { sector }\end{array}$} & \multicolumn{2}{|c|}{$\begin{array}{l}\text { Credit to } \\
\text { Government }\end{array}$} & \multicolumn{2}{|l|}{ M1 } & \multicolumn{2}{|l|}{ M2 } & \multicolumn{2}{|c|}{ Inflation } & \multicolumn{2}{|c|}{$\begin{array}{l}\text { Fiscal Deficit as } \% \text { of } \\
\text { GDP }\end{array}$} \\
\hline & Tgt & Out & Tgt & Out & Tgt & Out & Tgt & Out & Tgt & Out & Tgt & Out \\
\hline 1980 & & & & & & & & & & 9.9 & & -3.98 \\
\hline 1981 & & & & & & & & & & 20.9 & & -8.19 \\
\hline 1982 & & & & & & & & & & 7.7 & & -12.44 \\
\hline 1983 & & & & & & & & & & 23.2 & & -6.34 \\
\hline 1984 & & & & & & & & & & 39.6 & & -4.46 \\
\hline 1985 & 7.4 & 9.6 & 7.1 & 6.3 & 6.5 & 11.1 & $*$ & 12.4 & 30 & 1.03 & & -4.48 \\
\hline 1986 & 12.8 & 29.4 & 5.9 & -3.8 & 7.8 & -2.3 & $*$ & 4.2 & $* * *$ & 13.8 & & -11.94 \\
\hline 1987 & 8.4 & 19.6 & 1.5 & 13.8 & 11.8 & 12.1 & $*$ & 22.9 & $* * *$ & 9.7 & & -5.60 \\
\hline 1988 & 13.3 & 16.3 & 2.5 & 31.9 & 15.0 & 46.3 & $*$ & 35 & $* * *$ & 61.2 & & -8.74 \\
\hline 1989 & 10.7 & 16.4 & 8.3 & -74.9 & 14.6 & 18.2 & $*$ & 3.5 & $* * *$ & 44.7 & & -6.98 \\
\hline 1990 & 15.8 & 19.5 & 10.9 & 209.4 & 13.0 & 49.1 & $*$ & 45.9 & $* * *$ & 3.6 & & -8.27 \\
\hline 1991 & 16.4 & 18.7 & 0.0 & 74.0 & 14.6 & 27.9 & 19.8 & 27.4 & 13 & 22.3 & & -11.48 \\
\hline 1992 & 17.7 & 90 & 7.7 & 129.9 & 24.3 & 51.7 & 26.8 & 47.5 & 5 & 48.8 & & -7.42 \\
\hline 1993 & 20 & 19.5 & 14.5 & 103.2 & 20 & 56.3 & 18 & 53.8 & 25 & 61.3 & & -9.53 \\
\hline 1994 & 32.2 & 58.1 & 0.0 & 55.6 & 21.4 & 42.6 & 14.8 & 34.5 & $* * *$ & 76.8 & & -7.81 \\
\hline 1995 & 21.9 & 40 & 5.6 & -8.7 & 9.4 & 18.9 & 10.1 & 19.4 & 15.0 & 51.6 & & 0.05 \\
\hline 1996 & 29.5 & 23.3 & 0.0 & -58.0 & 14.5 & 12.9 & 16.8 & 16.2 & 30.0 & 14.3 & & 1.19 \\
\hline 1997 & 45.4 & 22.6 & 0.0 & -58.3 & 13.5 & 18.1 & 15.0 & 16.0 & 15.0 & 10.2 & & -0.18 \\
\hline 1998 & 33.9 & 16.6 & 0.0 & 210.9 & 10.2 & 18.6 & 15.6 & 23.3 & 9.0 & 11.9 & & -4.92 \\
\hline 1999 & 19.9 & 29.2 & 10.2 & 26.4 & 4.1 & 23.4 & 10.0 & 33.1 & 9.0 & 0.2 & & -8.93 \\
\hline 2000 & 21.9 & 30.9 & 37.8 & -170.1 & 9.8 & 62.2 & 14.6 & 48.1 & 9.0 & 14.5 & & -2.26 \\
\hline 2001 & 22.8 & 43.5 & 2.6 & 95.2 & 4.3 & 28.1 & 12.2 & 27 & 7.0 & 16.5 & & -4.68 \\
\hline 2002 & 34.9 & 11.8 & 96.6 & 6320.6 & 12.4 & 15.9 & 15.3 & 21.6 & 9.3 & 12.2 & & -4.36 \\
\hline 2003 & 32.3 & 26.8 & -150.3 & 58.4 & 13.8 & 29.5 & 15.0 & 24.1 & 9.0 & 23.8 & 3.0 & -2.39 \\
\hline 2004 & 22 & 26.6 & 29.9 & -17.9 & 10.8 & 8.6 & 15.0 & 14.0 & 10.0 & 10.0 & 3.0 & -1.51 \\
\hline 2005 & 22 & 30.8 & -10.9 & -36.99 & 11.4 & 29.7 & 15.0 & 24.4 & 10.0 & 11.6 & 3.0 & -1.11 \\
\hline 2006 & 30 & 32.1 & NA & -732.8 & NA & 32.2 & 27 & 43.1 & 9.0 & 8.6 & 3.0 & -0.55 \\
\hline 2007 & 30 & 91.6 & NA & -22.3 & NA & 37.6 & 24.1 & 44.8 & 9.0 & 6.6 & 3.0 & -0.5 \\
\hline 2008 & 54.7 & 59.5 & -54.6 & -31.2 & NA & 56.1 & 45.0 & 57.9 & 9.0 & 15.1 & 3.0 & -0.2 \\
\hline 2009 & 45 & 26.5 & 21.9 & 25.9 & 32.2 & 2.4 & 20.8 & 17.1 & 9.0 & 13.9 & 3.0 & -3.7 \\
\hline 2010 & 31.5 & -3.8 & 51.4 & 51.3 & 22.4 & 11.1 & 29.3 & 6.9 & 11.2 & 11.8 & 3.0 & -3.7 \\
\hline 2011 & 23.3 & 44.3 & 29.3 & 55.7 & NA & 21.5 & 13.8 & 15.4 & 12.0 & 10.3 & 3.0 & -3.2 \\
\hline 2012 & 47.5 & 6.8 & 61.5 & -393.8 & NA & 9.6 & 24.6 & 16.4 & 9.5 & 12.0 & 3.0 & -2.4 \\
\hline
\end{tabular}

\section{Sources: Statistical Bulletin 2008, 2012 Golden Jubilee Edition Table A.1.3.2 Ojo, 2000;} Sanusi, 2002

*Quantitative target for M2 not specified.

***Policy statement specified as significantly reduce/moderate the rate of inflation. 


\section{Challenges of Monetary and Fiscal Policies in Nigeria}

The effectiveness of monetary policy which is a key element to macroeconomic management is to Nigeria's overall economic performance and prospects. It has a critical role in ensuring an overall macroeconomic stability in the country. This role can be effectively performed only if the Central bank is allowed to perform its operation without unnecessary interference. Despite the fact that the Government recognizes the Bank's independence through the autonomy granted in 1999, short-term developments in the financial markets, which not consistent with government's short-term objectives, poses serious threat to this independence.

The issue of complementarity of monetary and fiscal policies is also very important. A situation where monetary policy stance is restrictive to stem the overheating of the economy and fiscal policy is expansionary; the efficacy of monetary policy is undermined and diminished, instead of the two complementing each other. The situation becomes even complicated especially when this expansionary fiscal stance is financed by the banking system. In this wise, there should be coordination of the monetary and fiscal policies to ensure successful macroeconomic stabilization.

Other challenges hindering the attainment of a sound fiscal policy management in Nigeria include lack of coordination among the three tiers of government, lack of agreement over broad macroeconomic objectives to be achieved and the management of oil windfall among others. Since about 50 per cent of total revenue goes to state and local governments. The implication is that all tiers of governance have considerable financial resources at their disposal and as such determines fiscal policy in Nigeria. Therefore any reckless spending at that level will overheat the economy.

The usefulness of data in policy formulation cannot be overemphasized. However, the formulation of sound policy in the country has been affected by the problem of inadequate, untimely and unreliable data. Another challenge is the persistence of infrastructure bottlenecks making it imperative for producers to make arrangements for their own power supply, water supply, and even security thereby increasing the cost of doing business. Moreover, the issue of corruption resulting in limited funds being available for programme implementation and the incidence of poor quality of work and service delivery, limited national capacities for programme implementation.

\section{Way Forward}

The state and local governments need to increase the pace of their move towards fiscal responsibility, accountability, transparency and integrity. There is need for diversification of the revenue base of the economy. In addition, there is need for fiscal policy coordination between federal and state governments and this coordination must be based on principles of transparency and accountability as well as respect for the constitution and the rule of raw. This will go a long way to accelerate growth, wealth creation and development. There is need to address the infrastructure needs in the economy as this would boost the development of the private sector. In addition, increased investment in the agricultural sector would bring more-employment and wealth-creation opportunities. 
To this end, efforts must be geared towards increasing private sector and government investment if more rapid growth and employment creation are to be achieved and sustained. The problem of poor performance and instability in the Nigerian economy is mismanagement and corruption. These issues need serious attention. In addition, the issue of transparency and accountability is also critical. Therefore, due process and discipline should be honestly restored in governance to avoid unnecessary policy failure.

There is need to strengthen the institutions that are in charge of production and analysis of data in the country so that their capacity to generate and utilize the available information can be enhanced. The fight against corruption should be intensified through speedy prosecution of cases in courts. This would assist in sending the right signals to corrupt government officials.

\section{References}

Baunsgaard, T. (2003). Fiscal Policy in Nigeria: Any Role for Rules? IMF Working Paper No. 155. July 2003

Busari, D. T., Omoke, P. C., \& Adesoye, B. (2010). Monetary Policy And Macroeconomic Stabilization under Alternative Exchange Rate Regime: Evidence from Nigeria. www.unionbankng.com/busari_.pdf 14/4/2010

Busari, T. D., \& Olayiwola, K. W. (1999). Stabilization Policy in Nigeria under Alternative Exchange Rate Regimes: A Postulated Empirical macro-Model Approach. Central Bank of Nigeria Economic and Financial Review, 37(1), 21-35.

Caballero, R. J. \& Corbo, V. (1989). The Effect of Real Exchange Rate Uncertainty on Exports: Empirical Evidence. World Bank Economic Review, 3, 263-278. http://dx.doi.org/10.1093/wber/3.2.263

CBN. (2010). Monetary Policy Implementation Framework Outcome. Retrieved from www.cenbank .org/out/eduseries 14/4/2010

CBN. (2012). Statistical Bulletin.

Chuku, A. C. (2009). Measuring the Effects of Monetary Policy Innovations in Nigeria: A Structural Vector Autoregressive (Svar) Approach African Journal of Accounting, Economics, Finance and Banking Research Vol. 5. No. 5. 2009

Ezeoha, A., \& Uche, C. U. (2006). Rethinking Monetary and Fiscal Policies in Nigeria. Journal of Sustainable Development in Africa, 8(2), 94-115.

Folawewo, A. O., \& Osinubi, T. S. (2006). Monetary Policy and Macroeconomic Instability in Nigeria : A Rational Expectation Approach. Journal of Social Sciences, 12(2), 93-100

Nnanna, O. J. (2001). Monetary Policy Framework in Africa: The Nigerian Experience. http://www.reservebank.co.za/internet/Publication.14/4/2010

Obinyelaku, M. (2006). Fiscal Policy Rules in Nigeria: Fixed or Variable? A paper presented at African Econometric Society Conference July 5-7, 2006 


\section{Macrothink}

Ojo, M. O. (2000). The Role of The Autonomy of the Central Bank of Nigeria (CBN) in Promoting Macroeconomic Stability. CBN Economic \& Financial Review, 38(1)。

Okonjo-Iweala, N., \& Osafo- Kwaako, P. (2007). Nigeria's Economic Reforms Progress and Challenges. Global Economy and Development Program The Brookings Institution Working Paper, No. 6

Olomola, A. S. (2009). Strategies and Consequences of Budgetary Reforms in Nigeria. A Paper Presented at the $65^{\text {th }}$ Annual Congress of the Institute of International Public Finance (IIPF), Cape Town, South Africa

Oluba, M. (2008). Has Nigeria's Monetary Policies Truly Supported Sustainable Macroeconomic Performance? Economic Reflections, B(20), August 2008

Sanusi, J. (2002). Nigeria's Macroeconomic Position: Controlling the Money Supply. A Presentation at the Meeting of the Honorary Presidential Advisory Council on Investment in Nigeria (HPACI), Hilton Hotel, Park Lane, London, UK. 17 July

Shamsuddeen U. (2008). Fiscal Policy, Poverty and Growth: The Nigerian Perspective. A paper presented at the 2nd Clement Isong Annual Memorial Lecture, Uyo, Akwa Ibom State.15th February.

Uchendu, (2009). Monetary Policy Management in Nigeria in the Context of Uncertainty. http://www.naijalowa.comwp-contentuploads19/5/2010

Ukwu I. U., Obi, A. W., \& Ukeje, S. (2003). Policy Options For Managing Macroeconomic Volatility In Nigeria.

\section{Copyright Disclaimer}

Copyright for this article is retained by the author(s), with first publication rights granted to the journal.

This is an open-access article distributed under the terms and conditions of the Creative Commons Attribution license (http://creativecommons.org/licenses/by/3.0/). 